\title{
EMPLOYEE PERCEPTIONS REGARDING WHISTLE-BLOWING IN THE WORKPlACE: A SOUTH AfricAN PERSPECTIVE
}

\author{
SANDRA PERKS \\ ELROY E SMITH \\ Department of Business Management \\ Nelson Mandela Metropolitan University \\ South Africa \\ Correspondence to: Sandra Perks \\ e-mail: Sandra.perks@nmmu.ac.za
}

\begin{abstract}
The purpose of whistle-blowing is to eradicate unethical behaviour in the work place. This article investigates the perceptions of South African employees $(n=387)$ employed in medium and large organisations regarding whistle-blowing. Respondents regard personal viewpoints and the supportive organisational environment as determining factors for whistle-blowing. South African employees have faced minimal negative consequences and will again engage in whistle-blowing, regardless of union support. Organisations can create a whistle-blowing culture by having a personal code of ethics, using hotlines, having an ethical committee, engaging in periodic ethics training and doing an annual ethical audit.
\end{abstract}

Keywords: ethical behaviour, internal policies, communication channels, whistle-blowing, wrongdoing.

While South Africa's transition to democratic rule has been characterised by high levels of crime, including widespread corruption, it does not detract from the moral issue that as individuals, each employee ought to be held accountable and responsible for his or her actions (Sangweni, 2005). Borrie and Dehn (2003) blame rapid advances in the transformation of the modern organisation for making it increasingly difficult for an organisation to have the necessary checks and controls in place, and this makes it easier for employers and employees to act in ways that compromise their professional integrity. To be effective in the fight against unethical behaviour in the work place, a wide-spread commitment to eradicate this behaviour is required. According to Daft (2006), organisations can no longer rely exclusively on codes of conduct and ethical structures to prevent all unethical behaviour, but have to depend to some degree on individuals who are willing to blow the whistle if they detect illegal, dangerous or unethical activities. Rossouw (2002) recommends that the responsibility to eliminate unethical behaviour should be shared by all members of the organisation. Members need to share a firm conviction that the tolerance of unethical behaviour is not in their own, or the organisation's interests, and that the eradication of unethical behaviour must become internalised.

Whistle-blowing is a very important ethical issue as it guards against the negative social, economic and environmental impact of multi-national corporations invading global markets. It also acts against the aggressive and unethical practices engaged in by such firms in order to earn revenue, particularly in the modern technologically-driven and turbulent economic times (Weiss, 2006). Whistle-blowing is considered a key tool for promoting individual responsibility and organisational accountability (Stewart, 1996).

Whistle-blowing is contrary to the tradition that an employee does not question a superior's decisions and acts, especially not in public. What is at stake is the employee's right to speak out in cases where they think the organisation or management is engaging in an unacceptable practice. If employees conclude that they cannot discuss current or potential unethical activities with co-workers or superiors, they may go outside the organisation for help (Carroll \& Buchholtz, 2000). Whistleblowing is thus a serious action with real consequences. It often involves a decision to be made among conflicting moral, legal, economic, personal, family, and career demands and choices.

Firstly, the objectives of the article are outlined, followed by the hypotheses with an explanation of how they were identified. Whistle-blowing is defined, the process is described and highlighted in a global context. The literature study explored the consequences of whistle-blowing and how to minimise wrongdoing in the work place. The research methodology outlines how the study was conducted, followed by the results with the implications and recommendations derived from the results. Guidelines are given on how to minimise wrongdoing in the workplace and the main conclusions of the study are highlighted.

\section{OBJECTIVES}

The primary objective of this article is to investigate the perceptions of employees regarding whistle-blowing in the workplace. To help achieve this main objective, the following secondary goals are identified:

- To explore the concept of whistle-blowing.

- To highlight the importance and nature of whistle-blowing as an ethical issue in the workplace.

- To empirically assess the perceptions of employees regarding whistle-blowing.

- To investigate the consequences of engaging in the act of whistle-blowing in the workplace.

- To identify and recommend organisational practices to minimise wrongdoing in the workplace.

\section{Hypotheses}

Various null-hypotheses were formulated to investigate the relationship between the independent variables (classification data) and dependent variables (perceptions regarding whistleblowing). The following null-hypotheses were formulated and tested:

$\mathrm{HO}_{1}$ There is no relationship between the personal viewpoints of respondents regarding whistle-blowing and their age.

$\mathrm{HO}_{2}$ There is no relationship between the personal viewpoints of respondents regarding whistle-blowing and their number of dependents. 
$\mathrm{HO}_{3}$ There is no relationship between the personal viewpoints of respondents regarding whistle-blowing and their ethnic group.

$\mathrm{HO}_{4}$ There is no relationship between the personal viewpoints of respondents regarding whistle-blowing and their position in the organisation.

$\mathrm{HO}_{5}$ There is no relationship between the personal viewpoints of respondents regarding whistle-blowing and their income level.

$\mathrm{HO}_{6}$. There is no relationship between a supportive environment for whistle-blowing and the ethnic group of respondents.

$\mathrm{HO}_{7}$ There is no relationship between a supportive environment for whistle-blowing and the position of respondents in the organisation.

$\mathrm{HO}_{8}$ There is no relationship between a supportive environment for whistle-blowing and the length of employment of respondents.

HO There is no relationship between a supportive environment for whistle-blowing and the income level of respondents.

With regards to the analysis of variance exercise, 10 independent variables (classification data) and five dependent variables/ factors (whistle-blowing) were used. A total of 50 hypotheses were originally formulated and tested by means of ANOVA (41 null-hypotheses indicated no relationships between the tested variables). Only the nine hypotheses (Hypothesis $\mathrm{H}_{1}$ to Hypothesis $\mathrm{H}_{\mathrm{g}}$ ) indicating significant relationships are outlined above and reported in this article.

Five other null hypotheses (Hypothesis $\mathrm{H}_{10}$ to Hypothesis $\mathrm{HO}_{14}$ ) investigate the consequences of whistle-blowing and are reported elsewhere in this article. The alternative or research hypotheses could be stated as the exact opposite of the abovementioned null hypotheses (Hypothesis $\mathrm{H}_{1}$ to Hypothesis $\mathrm{H}_{14}$ ).

\section{Whistle-blowing in the workplace}

Concept clarification

Eaton and Akers (2007) explain that whistle-blowing in its simplest form involves the act of reporting wrongdoing within an organisation to internal and/or external parties. Daft (2006) stipulates that whistle-blowing is the employee's disclosure of illegal, immoral, or illegitimate practices on the employer's part. Hellriegel, Jackson, Slocum, Staude and Associates (2001) define whistle-blowers as employees who report unethical or illegal actions of their employers to other people or organisations that are capable of taking corrective action. Camerer (2001) regards whistle-blowing in its most general form as involving calling public attention to wrongful acts, typically in order to avert harm.

For the purpose of this study, whistle-blowing is defined as when an employee reveals wrongdoing within an organisation either to the public or to those in positions of authority.

\section{Channels}

Camerer (1996) comments that the whistle-blower must preferably blow the whistle through available internal channels or, as a last resort, to a regulatory body, the press or police. Unfortunately, according to Sangweni (2005) most employees are too scared to blow the whistle internally as they might be disadvantaged, disciplined or dismissed. Alternatively, Auriacombe (2005) confirms that if blowing the whistle to an outside party such as the press, the whistle-blower could experience negative reaction from the organisation, supervisors or colleagues.

Process

The whistle-blowing process is depicted in Figure 1 below. It clearly shows the authority lines to follow for lodging the wrongdoing as well as the actions required by each superior.

The above indicates the process that organisations can follow to increase public scrutiny of corporate behaviour. Ravishankar (2002) added to this by outlining the following steps for creating a whistle-blowing culture in an organisation:

- Step 1: Create a policy with formal mechanisms, clear communication lines and clear communication about bans on retaliation;

- Step 2: Get endorsement from top management (CEO to line managers) for an open-door policy regarding employee complaints

Whistle-blower reports to line manager

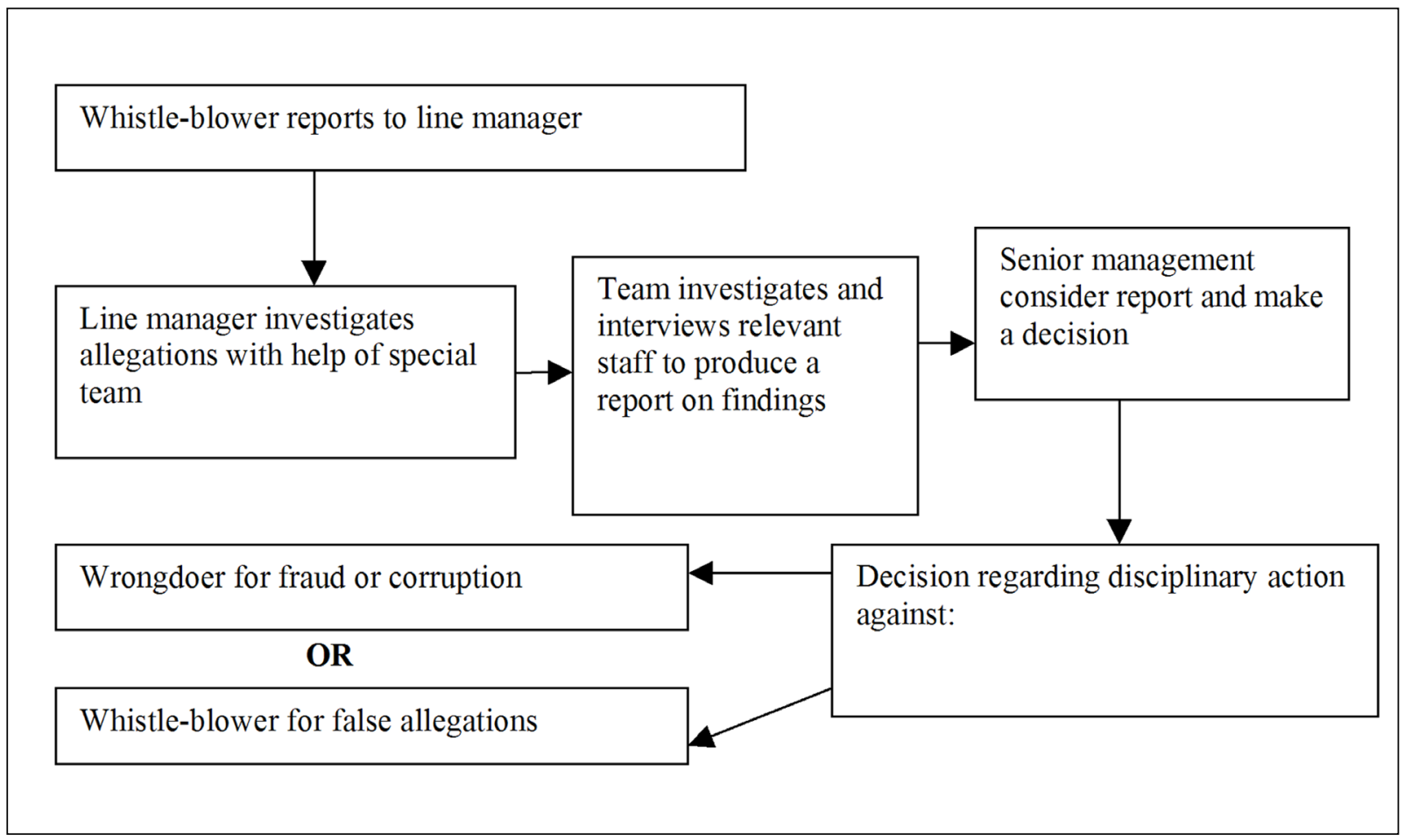


- Step 3: Publicise the organisation's commitment through newsletters, memos and speeches acknowledging and rewarding employees who report ethical issues;

- Step 4: Investigate and follow up all investigations promptly and thoroughly and report the origins and results to a higher authority;

- Step 5: Assess the organisation's internal whistleblowing system through employees' opinions about the organisational culture and commitment to ethics and values.

The first step will be to outline a whistle-blowing process and then to outline how whistle-blowing can be incorporated in the organisational culture. In the next section the consequences of whistle-blowing are explored.

Consequences of whistle-blowing

Dellaportas, Gibson, Alagiah, Hutchinson, Leung and Van Homrigh (2005) warn that while whistle-blowers are considered heroes by the public, within the organisation, the whistle-blower is considered a traitor who has been disloyal to the organisation and colleagues. Rossouw and Van Vuuren (2004) agree that although legal protection is an avenue that can be visited by the whistle-blower, it has a devastating effect, especially when it results in losing one's job. Dellaportas et al. (2005) cited examples in history where whistle-blowers were penalised for their actions by: some form of harassment, lower performance evaluations, demotions, punitive transfers and dismissal. Whistle-blowers are also ostracised by management and colleagues as troublemakers, which in turn hinders future employment opportunities. Nelson and Trevino (2007) cautioned employees on deciding how to raise ethical concerns in order to avoid being branded as someone with poor judgment. Other risks the whistle-blower can face include disciplinary hearings for insubordination, claims of disloyalty, accusations of whistle-blowing for personal gain, loss of friendships and loss of respect for the ethnicity in whose interest the whistleblower acted (Naude, 2005).

Camerer (1996) states that the culture of the organisation determines whether the whistle-blower will be considered as a wrongdoer, or as a do-gooder, regardless of whether the whistle has been blown through internal channels or, as a last resort, through external channels. Dellaportas et al. (2005) regards the negative effects of whistle-blowing for the organisation, besides bad publicity, as a negative reputation, prosecution, decreased profits and the demoralisation of the workforce. The ramifications for both the employee and the organisation are serious, and procedures and practices need to be in place to help smooth the process.

According to Wood (2004), whistle-blowers may face fierce resistance and extreme levels of disapproval inside the organisation when they attempt to expose unethical and suspect behaviour. Whistle-blowers may be discredited by transferring them to undesirable duties or shifts. Kaplan and Kleiner (2000) cited that whistle-blowers often face different forms of retaliation, for example by:

- putting the spotlight on the whistle-blower;

- manufacturing a poor record;

- being threatened to silence, isolation or humiliation,

- setting them up for failure;

- prosecution;

- eliminating their jobs, or

- paralysing their careers.

Carroll and Buchholtz (2000) stated that studies of whistleblowers have found that as many as $90 \%$ experience negative outcomes, and more than half lose their jobs. Many end up taking prescription medicine to ease the stress, while others even contemplate suicide. In spite of this, Dellaportas et al. (2005) advise that employees should be encouraged to blow the whistle internally and to resolve the problem before it becomes a public scandal. If the employees remain silent they could be labelled accomplices if the wrongdoing is later revealed.

Based on the above-mentioned reasoning, the following null hypotheses were formulated to investigate the consequences of whistle-blowing in the workplace:

$\mathrm{HO}_{10 .}$. Blowing the whistle does not lead to any consequences.

$\mathrm{HO} \mathrm{H}_{11}$ Blowing the whistle does not result in large-scale resignation for whistle-blowers.

$\mathrm{HO}_{12}$ Unions do not protect employees if fired for blowing the whistle.

$\mathrm{HO}_{13}$ Previous whistle-blowers intend not to engage in the act of future whistle blowing.

$\mathrm{HO}_{14}$ Most whistle-blowers do not report wrongdoing to the organisation itself.

The next section highlights some global whistle-blowing practices.

\section{Global whistle-blowing practices}

In South Africa, the Protected Disclosure Act, No. 26 came into force in February 2001 to protect whistle-blowers, both in the public and private sector. Prior to this Act, there were other efforts, which include the Promotion of Access to Information Act and hosting of anti-corruption conferences in 1998 and 1999. At the 1999 conference resolutions were taken to develop, encourage and implement whistle-blowing mechanisms to protect people from victimisation when they expose corruption. (Whistle-blowing Act No. 26, 2000).

Literature about whistle-blowing from the following key countries reveals the following global legal practices to minimise wrongdoing in the workplace (Classified and Related Information Disclosure Act 1998; Caslon Analytics guide secrecy and accountability 2000; Hills Governance Centre, 2004; Policy and procedures on whistle-blowing: Definition, 1999; Ravishankar, 2002):

- Whistle-blowers Protection Act in Australia (Victoria - 2001; Queensland - 1994);

- United Kingdom Public Interest Disclosures Act - 1998;

- United States Whistle-blower's Protection Act - 1989;

- Japan's Whistle-blower Protection Act - 1994;

- South Korea's Anti-corruption and Protection Act - 2001;

- New Zealand Public Service Whistle-blowing Act - 2000.

Other countries that have followed are Ghana and Philippines (Hills Governance Centre, 2004; Martens \& Crowell, 2002). Within these Acts provision is made for a code of conduct, the protection of the whistle-blower, whistle-blowing channels, procedures and support structures for, and programmes to promote whistle-blowing (Hills Governance Centre, 2004). Most of the above-mentioned countries allow whistle-blowing to external channels but procedures differ in the various countries. In Australia, the United States and New Zealand, annual reports must be released specifying the current guidelines, the number of disclosures investigated and referred to other public agencies (Hills Governance centre, 2004). In the United States, the AIG Corporate Compliance group has established a toll-free help line to report suspected misconduct or fraud. Countries outside the United States can also call this line or report online (Dom, 2007). According to Martens and Crowell (2002) in China hotlines are not favoured as it reminds employees of the horror of the Cultural Revolution, also not in Germany as it reminds employees about Gestapo tactics. Scepticism exists about the reality of whistle-blowers' protection in Hong Kong, Taiwan and China (Martens \& Crowell, 2002). It is further stated that in Russia whistle-blowers subject themselves to a lot of trouble due to possible persecution from company managers and/or owners. Hills Governance Centre (2004) remarked that in Japan 
and Australia granting of rewards linked to whistle-blowing is not explicit in the whistle-blowing acts. The European Union published a charter for whistle-blower protection in 2000 (Martens \& Crowell, 2002).

In South Africa, a company called Whistle Blowers (Pty) Ltd offers a 24-hour communication centre for reporting wrongdoing and crime prevention. It is more than a hotline as it also assists in the investigation and provides feedback to the parties (Whistle-blowers, 2007). Johnnic Communications in South Africa also advertise their anonymous independent hotline for reporting workplace dishonesty. In the next section further organisational practices for minimising wrongdoing are outlined.

\section{Organisational practices for minimising wrongdoing}

Sangweni (2005) identifies several initiatives that have been undertaken in South Africa by government to promote accountability and fight corruption within the public sector. These include legislation on the Promotion of Access to Information Act and the Protected Disclosure Act. This Act aims to protect persons from victimisation when they expose corruption and unethical practices. Government has also hosted various anti-corruption conferences.

Barker and Dawood (2004) recommend that organisations implement an effective internal system for employees to raise concerns and to facilitate the process of whistle-blowing internally. If individuals feel that it is not safe and accepted to blow the whistle internally, they will resolve to blow the whistle externally. Megone and Robinson (2002) suggest that the internal policy on whistle-blowing should include: a clear statement that malpractices are taken seriously, confidentiality is respected, that there are penalties for false and malicious allegations and/or a clear indication of how the concern can be raised externally if necessary. The internal system should include proper communication channels, commitment by management to the whistle-blowing process and to support the whistle-blower. Barker and Dawood (2004) and Ravishankar (2002) propose paying attention to formal mechanisms for reporting violations, such as:

- hotlines and mailboxes;

- respect for the confidentiality of staff raising concerns;

- access to independent advice, and

- guidelines on how to raise concerns outside the organisation if deemed necessary.

Brian (2001) stressed that the practice of whistle-blowing must be communicated by line managers at all levels who are trained continuously in creating an open-door policy regarding employee complaints. To create a culture of openness and honesty, it is important that employees are reminded regularly about the policy. This will require management to investigate all allegations promptly and thoroughly, and report the origins and the results of the investigation to a higher authority. Robbins and Judge (2006) encourage ethics training to implement an ethical organisational culture. The training should be given to new employees as part of orientation, as well as to existing employees. This training should be given on a periodic basis to help employees recognise ethical dilemmas and to make them aware of the ethical issues underlying any action they take (Robbins \& Judge, 2006). It could also serve as reinforcement of ethical principles.

A large organisation has the ability to develop and implement various programmes to minimise wrongdoing. De Beers has a fully outsourced ethics hotline (Investing in the future, 2005) and a principles assurance programme which encourages the systematic monitoring of performance, third party verification and has a commitment to disclosure (About De Beers, 2005). Ten things you can do to avoid being the next Enron (2005) gives the following guidelines on how to minimise wrongdoing and to improve an ethical climate:

- Organisations should examine their ethical climate and put safeguards in place. These include conducting a formal assessment of their corporate culture from the perspectives of attitudes, perceptions, standards of conduct and vulnerabilities.

- Organisations should also have ethics committees who are responsible for ensuring that systems are in place in the corporation. These committees should also focus on employee compliance with the Code of Ethics.

- "Hot lines" can also help employees - they can phone when they are confronted with an ethical dilemma.

- Communication is also an important element to ensure that wrongdoing is eliminated. Managers should communicate values and be supportive of employees that may have a problem.

- Codes of conduct or an ethics code should be properly implemented. It is no use having a wonderful code of conduct that employees are not aware of. Management should post ethic codes on information boards, intranets and in annual reports.

Moon and Bonny (2001) agree with Ten things you can do to avoid being the next Enron (2005) that companies should establish codes of conduct or adopt the International Chamber of Commerce's revised code to ban any form of unethical behaviour by company employees. Organisation Ethics policy (2005) indicated that management is responsible both for ensuring that policies and procedures are in place to manage risks or unethical practices and for complying with such policies and procedures. More should be done than merely investing in closed circuit television to combat intra-organisational crime (Organisations learn ethics make good organisation sense, 2003). Hellriegel, Jackson, Slocum, Staude \& Associates (2004) identify the practices outlined in Table 1 to encourage whistleblowing and minimise wrongdoing.

These previous suggestions will only be effective if, according to Nadler and Schulman (2006) an observer of wrongdoing is willing to make reports over the hotline, and those who receive the reports respond appropriately and ensure that theemployee's identity remains confidential. This will require commitmen from top management and they must be serious about corruption and wanting to create a supportive environment for whistle-blowers (Bakman, 2003). By preventing organisational wrongdoing, both the organisation and the individual benefit (Bakman, 2003).

TABLE 1

Practices to minimise wrongdoing

\begin{tabular}{|c|c|}
\hline NUMBER & PRACTICES TO MINIMISE WRONGDOING \\
\hline 1 & $\begin{array}{l}\text { Signal the importance of ethical conduct through the organisation's } \\
\text { vision and value statements. }\end{array}$ \\
\hline 2 & Have a designated ethics officer. \\
\hline 3 & Use an integrity test when screening job applications. \\
\hline 4 & $\begin{array}{l}\text { Provide ways for employees to report the questionable actions of } \\
\text { peers and superiors, such as providing an ethics hotline. }\end{array}$ \\
\hline 5 & $\begin{array}{l}\text { Develop enforcement procedures that contain stiff disciplinary and } \\
\text { dismissal procedures. }\end{array}$ \\
\hline 6 & $\begin{array}{l}\text { Treat allegations of wrongdoing seriously and treat both parties } \\
\text { fairly. }\end{array}$ \\
\hline 7 & $\begin{array}{l}\text { Document the organisation's ethical rules through a written Code } \\
\text { of ethics. }\end{array}$ \\
\hline 8 & $\begin{array}{l}\text { Appoint an ethics committee to implement organisation ethics } \\
\text { initiatives and supervise the ethics officers. }\end{array}$ \\
\hline 9 & Emphasise the importance of ethical conduct in training. \\
\hline 10 & $\begin{array}{l}\text { Conduct an ethical audit and take visible steps to address concerns } \\
\text { raised. }\end{array}$ \\
\hline 11 & $\begin{array}{l}\text { Constantly communicate the organisation's ethical standards and } \\
\text { principles. }\end{array}$ \\
\hline
\end{tabular}




\section{RESEARCH METHODOLOGY}

To investigate the perceptions of South African employees regarding whistle-blowing in the workplace, an empirical study was undertaken.

\section{Research approach}

The quantitative research method is used in this research project. It is a form of conclusive research, which involves a large representative sample and structured data collection procedures are used. The quantitative research approaches used are exploratory research (an area that has not been studied in order to develop initial ideas) and descriptive research (describe whistle-blowing perceptions of employees).

\section{The sample}

For the purpose of this research project the population could be regarded as all employees employed by firms employing more than 50 employees operating in the Nelson Mandela Metropole in Port Elizabeth, South Africa. Only medium and large organisations were targeted. A non-probability sampling procedure was used and a convenient sample was drawn, purely on the basis of availability and accessibility. Clear instructions were given regarding the sample and data collection procedure. The total sample size was 387 employees.

\section{The questionnaire}

Structured questionnaires were administered during personal interviews. The questionnaire is divided into three sections:

- Section A deals with the classification data of respondents (biographical details) and contains a nominal scale of measurement, using 10 categorical variables. Aspects covered included: gender, age, number of dependants, educational level, ethnic group, position in the organisation, length of employment, income level, size of organisation and type of employment.

- Section B investigated the whistle-blowing perceptions of employees in the workplace and consists of five factors: personal viewpoints regarding whistle-blowing, perceptions of colleagues' actions regarding whistleblowing, consequences of whistle-blowing, rewards and supportive environment. A total of 26 variables/statements are used. The type of ordinal scale used is a five-point Likerttype scale. One open-ended question was used to obtain suggestions for minimising wrongdoing in the workplace.

- Section C deals with the consequences of whistle-blowing and was completed only by those employees who had previously engaged in the act of whistle-blowing. A nominal scale of measurement is used, consisting of five dichotomous statements related to the consequences of whistle-blowing. One open-ended question was used (year in which whistleblowing occurred).

\section{Pilot study}

In order to pre-test the questionnaire, it was given to a few fulltime employed students and a few academics in the field of management, human resources and statistics. After processing and analysing the data from this pilot study, the questionnaire was refined and some minor changes were made regarding wording, sequence and layout.

\section{TABLE 2}

Descriptive statistics for whistle-blowing perceptions

\begin{tabular}{lccc}
\hline FACTOR/VARIABLE & MEAN & RANGE & VARIANCE \\
\hline $\begin{array}{l}\text { Personal viewpoints regarding whistle- } \\
\text { blowing (B1) }\end{array}$ & 3.15 & 2.33 & 0.55 \\
$\begin{array}{l}\text { Perceptions about colleagues' actions } \\
\text { regarding whistle-blowing (B2) }\end{array}$ & 3.25 & 0.87 & 0.14 \\
Consequences of whistle-blowing (B3) & 2.73 & 0.87 & 0.97 \\
Rewards for whistle-blowing (B4) & 3.04 & 0.20 & 0.02 \\
Supportive environment (B5) & 3.35 & 1.58 & 0.27 \\
\hline
\end{tabular}

\section{Data collection}

The type of information required (data specification decisions) for this research project can be classified as follows:

- Type of data - research data are numeric and verbal (interviews).

- Sources of data - both secondary and primary data (survey) were collected.

- Nature of data - data were collected at a single point in time.

- Form of data - overt data by means of interviews.

During the literature search (secondary data collection), various textbooks, journals and the Internet were consulted. Primary data were collected by means of a survey through structured questionnaires administered during personal interviews. A total of 387 questionnaires were completed during these personal interviews. Clear instructions were given regarding the completion of these questionnaires.

\section{Data processing and analysis}

The returned questionnaires were inspected to determine their level of acceptability. They were then edited where necessary, and coded. The data were transferred to an Excel spreadsheet. A statistical computer package, named SPSS, was used to process the results. Techniques used during data analysis included descriptive statistics (e.g. mean and variance), frequency distribution, factor analysis, correlation coefficients and analysis of variance.

\section{RESULTS}

\section{Descriptive statistics}

Table 2 provides an overview of the most important and significant descriptive statistics for Section B of the questionnaire (perceptions regarding whistle-blowing).

With regard to the descriptive statistics of each individual variable, noin-depth discussion is provided, as it falls beyond the scope of this article. Only those factors with significant statistics are reported. Regarding the measure of central tendency (mean values) of these factors, it appears that most of these values cluster around point three (neutral) on the instrument scale. It appears that most respondents are indifferent regarding the factors/variables testing perceptions about whistle-blowing. Respondents tend to disagree (point two on the scale) with the variables constituting factor B3 (consequences of whistleblowing). Measures of dispersion, indicated by means of low variance scores, reveal that respondents tended not to vary much regarding their opinions about these variables.

\section{Demographic profile of respondents}

Table 3 provides an outline of the most important demographic characteristics of respondents. Ten classification data variables were used in Section A of the questionnaire.

Table 3 highlights some of the most important demographic characteristics of respondents. Some of the categories were re-categorised for purpose of analysis. The majority of the respondents $(56 \%)$ were males. Forty-five percent of the respondents are between the ages of 25 and 34 . Half of the respondents ( $50 \%$ ) have one to three dependants, while $43 \%$ have no dependants. A significant percentage of the respondents (27\%) only have a grade 12 qualification, while $38 \%$ have a bachelor's degree or post-graduate degree ( $36 \%$ have a national certificate or diploma). The majority of respondents (43\%) were white, while blacks and coloureds were $33 \%$ and $18 \%$ respectively of the total sample. Sixty-six percent of the respondents were employees, while $29 \%$ occupied a managerial position and five percent were owners. Based on length of employment in the organisation, it appears that almost one fifth (19\%) of the 
TABLE 3

Frequency distribution results of classification dataptions

\begin{tabular}{|c|c|c|}
\hline CHARACTERISTIC & CATEGORY & $\%$ \\
\hline \multirow[t]{2}{*}{ Gender } & Male & 56 \\
\hline & Female & 44 \\
\hline \multirow[t]{6}{*}{ Age } & $18-24$ & 20 \\
\hline & $25-34$ & 45 \\
\hline & $35-44$ & 16 \\
\hline & $45-54$ & 15 \\
\hline & $55-64$ & 3 \\
\hline & $64+$ & 1 \\
\hline \multirow[t]{5}{*}{ Number of dependants } & None & 43 \\
\hline & 1 & 21 \\
\hline & $2-3$ & 29 \\
\hline & $4-5$ & 5 \\
\hline & $5+$ & 2 \\
\hline \multirow[t]{4}{*}{ Education } & Grade 12 & 27 \\
\hline & National certificate/diploma & 36 \\
\hline & Bachelor's degree & 23 \\
\hline & Post graduate qualification & 14 \\
\hline \multirow[t]{5}{*}{ Ethnic group } & White & 44 \\
\hline & Coloured & 18 \\
\hline & Black & 33 \\
\hline & Asian & 3 \\
\hline & Other & 2 \\
\hline \multirow[t]{3}{*}{ Position in organisation } & Owner & 5 \\
\hline & Manager & 29 \\
\hline & Employee & 66 \\
\hline \multirow[t]{5}{*}{ Length of employment } & $<1$ year & 19 \\
\hline & $2-5$ years & 39 \\
\hline & $6-10$ years & 21 \\
\hline & $11-15$ years & 10 \\
\hline & 15 years + & 11 \\
\hline \multirow[t]{4}{*}{ Income level } & $<$ R5000 & 17 \\
\hline & R5001-R12000 & 45 \\
\hline & R12001-R20000 & 22 \\
\hline & $\mathrm{R} 20001+$ & 16 \\
\hline \multirow[t]{2}{*}{ Size of organisation } & Medium & 40 \\
\hline & Large & 60 \\
\hline \multirow[t]{3}{*}{ Type of employment } & Permanent & 81 \\
\hline & Contract & 14 \\
\hline & Part-time & 5 \\
\hline
\end{tabular}

respondents have been employed for less than one year in the organisation, while the majority $(60 \%)$ have been employed for more than five or 10 years. Forty-five percent of the respondents earn a salary of between R5000 and R12000, while $17 \%$ earn a salary of less than R5000 and 38\% earn a salary of more than R12000. Sixty percent of the respondents are employed in a large organisation, with $40 \%$ in medium-sized organisations. It appears that the majority of respondents $(81 \%)$ are permanently employed, with the remainder on a contract or part-time basis.

\section{Frequency distribution results: consequences of whistle- blowing}

Table 4 indicates the frequency distribution results of the consequences of whistle-blowing (Section $\mathrm{C}$ of the questionnaire). It should be noted that only respondents who have engaged in the act of whistle-blowing completed this section of the questionnaire. A total of 147 respondents (38\%) had engaged in the act of whistle blowing.

Table 4 clearly indicates the possible consequences of whistleblowing for employees. The majority of respondents $(86 \%)$ indicated that they are still employed by the same organisation despite the fact that they have blown the whistle (14\% possibly
TABLE 4

Frequency distribution results of consequences of whistle-blowing

\begin{tabular}{llr}
\hline CONSEQUENCE & CATEGORY & $\%$ \\
\hline Still employed by same firm & Yes & 86 \\
& No & 14 \\
Treated fairly by organisation & Yes & 81 \\
& No & 19 \\
Year of whistle-blowing & $1985-1995$ & 7 \\
& $1996-2006$ & 77 \\
To whom wrong doing reported & $2007-$ currently & 16 \\
& Organisation & 78 \\
& Press & 3 \\
Union protection against possible dismissal & Police & 7 \\
& Other & 12 \\
Possibility of blowing the whistle again & No & 51 \\
& Yes & 49 \\
\hline
\end{tabular}

$n=147$

left as a result of whistle-blowing). It appears that the majority of respondents $(81 \%)$ were treated fairly by the organisation when engaging in the act of whistle-blowing. Since 1985 there has been a remarkable increase in the reporting of wrongdoing in South Africa. Seventy-seven percent of the alleged whistleblowing acts occurred between 1996 and 2006, while since last year $16 \%$ of whistle-blowing acts have occurred. Most of the wrongdoings were reported to the organisation itself $(78 \%)$, while $10 \%$ were reported to the press or police services. It appears that almost half of the respondents received protection from their union against possible dismissal because of engaging in whistle-blowing, while the other half did not receive any protection from their union. Most of the respondents (84\%) indicated that they are willing to blow the whistle in future if required to do so.

Based on the information provided in Table 4 above, this section attempts to provide the results of testing Hypothesis ${ }_{10}$ to Hypothesis ${ }_{14}$ (consequences of whistle-blowing). Only respondents who have engaged in whistle-blowing and reported wrongdoing completed Section $C$ of the questionnaire. It has been clearly indicated that blowing the whistle has certain consequences $\left(\mathrm{HO}_{10}\right.$ rejected). It could lead to resignation $(14 \%)$, being treated unfairly $(19 \%)$, having to report the wrongdoing to outsiders $(22 \%)$ and not receiving union protection against possible dismissal $(49 \%)$. The majority of respondents $(86 \%)$ are sill employed with the same organisation after blowing the whistle and only $14 \%$ resigned (this could have been for other reasons). These results thus contradict the findings of Carroll and Buchholtz (2000) that as many as $90 \%$ experience negative outcomes, and more than half lose their jobs. Based on this reasoning, Hyporthesis ${ }_{11}$ can be accepted, thus implying that whistle-blowing does not result in large-scale resignation of employees. Hypothesis ${ }_{12}$ is also rejected: $51 \%$ of the respondents indicated that they received some form of union protection against the possibility of getting fired for blowing the whistle. It is, however, regretful that the other $49 \%$ did not receive any union protection. It further appears that previous whistle-blowers are not reluctant to engage in future whistle-blowing (Hypothesis ${ }_{13}$ rejected) $-84 \%$ indicated that they will again blow the whistle. Based on the fact that $78 \%$ of the respondents indicated that they reported the wrongdoing to the organisation itself (only $22 \%$ reported it to outsiders), Hypothesis ${ }_{14}$ is rejected.

\section{Reliability and validity of the measuring instrument}

External validity refers to the generalisation of research results to other population groups and is ensured by means of a proper and sound sampling procedure. Clear guidance was given 
regarding the place, time and conditions in which the research was to be conducted. Internal validity of the instrument's scores is ensured through both face and content validity. Expert judgement and a pilot study were undertaken to assist in this regard. Internal consistency reliability was ensured by means of a factor analysis. The statistical software package, SPSS, was used to determine the Cronbach's alpha values for the four predetermined whistle-blowing factors. To confirm the internal reliability of the five factors, Cronbach's alpha was calculated (refer to Table 5).

According to Hair, Anderson, Tatham and Black (1998), Cronbach's alpha value may be decreased to 0.5 in exploratory research. It can therefore be concluded that all factors are internally reliable.

\section{Correlation}

An inter-item correlation exercise was conducted to determine the correlation between the variables constituting each factor. It can be reported that most of the variables in each factor show positive relationships with each other (indicating strong positive $r$ values). A positive correlation coefficient ( $r$ value) indicates a strong or positive relationship among the variables. Only in factor one (personal viewpoints) and factor five (supportive environment) a few negative correlation coefficients were identified. For example, item or variable B1 (willingness to report) correlated with B3 (preparedness to leave the firm) indicates a negative $r$ value of -.0336 while B19 (cannot report as supervisor is involved) correlated with B25 (availability of internal reporting procedure) indicates a negative $r$ value of -.0826 . All other correlations indicate strong positive relationships between the variables or items, but fall beyond the scope of this article and are thus not reported.

\section{ANOVA}

The purpose of this analysis is to investigate the relationship between the independent and dependent variables and to test the stated hypotheses. Inferential statistics are used to make

TABLE 5

Cronbach's alpha (Section B of the questionnaire)

\begin{tabular}{clc}
\hline VARIABLES & FACTOR & $\begin{array}{c}\text { CRONBACH'S } \\
\text { ALPHA }\end{array}$ \\
\hline $1-7$ & $\begin{array}{l}\text { Personal viewpoints regarding whistle- } \\
\text { blowing (B1) }\end{array}$ & 0.52 \\
$8-11$ & $\begin{array}{l}\text { Perceptions about colleagues' actions } \\
\text { regarding whistle-blowing (B2) }\end{array}$ & 0.60 \\
$12-16$ & Consequences of whistle-blowing (B3) & 0.55 \\
$17-18$ & Rewards for whistle-blowing (B4) & 0.78 \\
$19-26$ & Supportive environment (B5) & 0.66 \\
\hline
\end{tabular}

TABLE 6

Analysis of variance results for the variables

\begin{tabular}{lllll}
\hline \multicolumn{1}{c}{$\begin{array}{c}\text { DEPENDENT } \\
\text { VARIABLE }\end{array}$} & $\begin{array}{l}\text { INDEPENDENT } \\
\text { VARIABLE }\end{array}$ & F-TEST & P-VALUE & HYPOTHESIS \\
\hline $\begin{array}{l}\text { Personal viewpoints } \\
\text { regarding whistle- } \\
\text { blowing }\end{array}$ & Age & 6.427 & $0.000^{*}$ & $\mathrm{H} 1$ \\
& $\begin{array}{l}\text { Number of } \\
\text { dependents }\end{array}$ & 3.774 & $0.005^{*}$ & $\mathrm{H} 2$ \\
& $\begin{array}{l}\text { Ethnic group } \\
\text { Position in }\end{array}$ & 7.980 & $0.000^{*}$ & $\mathrm{H} 3$ \\
& $\begin{array}{l}\text { organisation } \\
\text { Income level }\end{array}$ & 3.857 & $0.000^{*}$ & $\mathrm{H} 4$ \\
\hline $\begin{array}{l}\text { Supportive } \\
\text { environment for } \\
\text { whistle-blowing }\end{array}$ & $\begin{array}{l}\text { Ethnic group } \\
\text { Position in } \\
\text { organization }\end{array}$ & 3.535 & $0.002^{*}$ & $\mathrm{H} 5$ \\
\hline & $\begin{array}{l}\text { Length of } \\
\text { employment }\end{array}$ & 4.335 & $0.004^{*}$ & $\mathrm{H} 6$ \\
& Income level & 4.610 & $0.002^{*}$ & $\mathrm{H} 7$ \\
& & $0.000^{*}$ & $\mathrm{H} 8$ \\
\hline
\end{tabular}

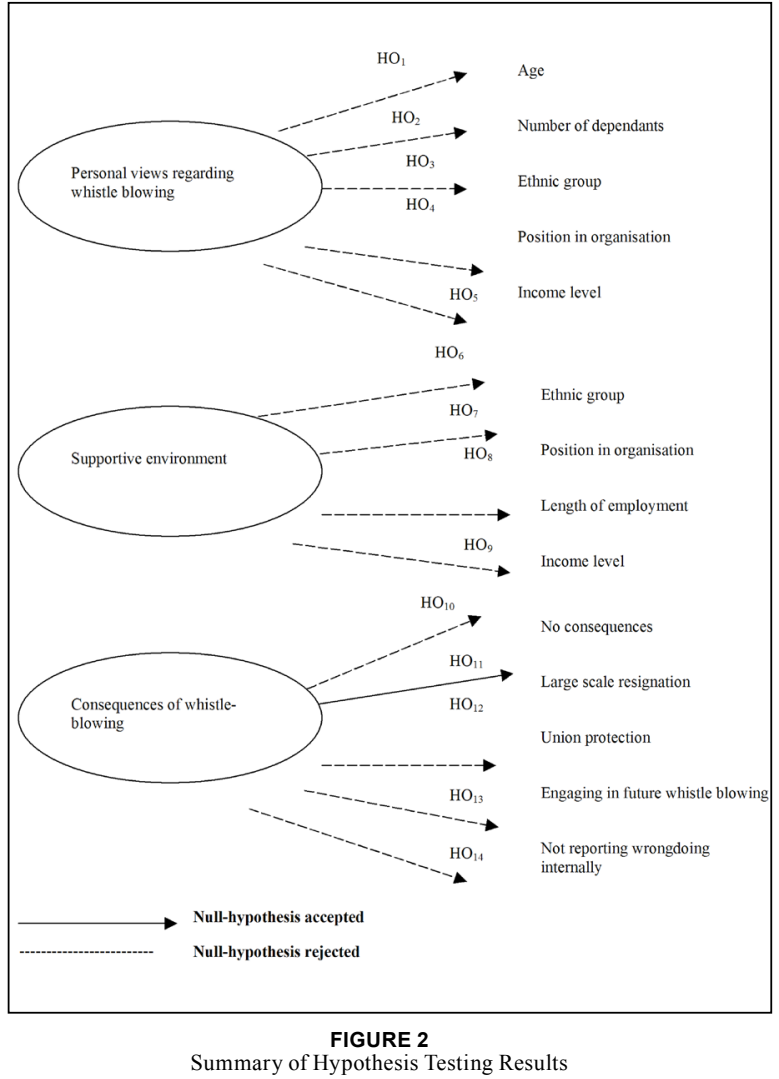

inferences about the population using sample data to make decisions regarding various hypotheses. Different analyses of variance exercises were conducted to test the stated hypotheses. The classification data variables are used as the independent variables (Section A of the questionnaire) and perceptions regarding whistle-blowing in the workplace are used as the dependent variables (Section B of the questionnaire). Table 6 only reports those ANOVA results that show significant relationships between the independent and dependent variables and those that exhibit no significant relationships are excluded.

The ANOVA results clearly indicate the relationships between the independent and dependent variables. Hypothesis 1 to Hypothesis $_{9}$ can, in all cases, be rejected and the alternative hypotheses can be accepted. Hypothesis 1 to Hypothesis ${ }_{5}$ fall within the rejection region $(p<0.01)$ which indicates that there is a significant relationship (difference) between personal viewpoints of respondents regarding whistle-blowing and the following classification data variables: age, number of dependants, ethnic group, position in organisation and income $\left(\mathrm{H}_{1}\right.$ to $\mathrm{H}_{5}$ accepted). Hypothesis to Hypothesis ${ }_{9}$ also fall within the rejection region: P-values $<0.01$ and large F-statistic values. This indicates that there are significant relationships between a supportive environment for whistle-blowing and the following classification data variables: ethnic group, position in organisation, length of employment and income level $\left(\mathrm{H}_{6}\right.$ to $\mathrm{H}_{9}$ accepted).

Figure 2 summarises the results of testing the hypothesis stated in the study.

\section{CONCLUSIONS AND RECOMMENDATIONS}

The following conclusions and recommendations can be drawn, based on the analysis of variance between the independent variables (classification data) and dependent variables (whistleblowing perceptions):

- There appears to be a highly significant relationship between age and personal viewpoints of employees regarding 
whistle-blowing ( $\mathrm{H}_{1}$ rejected). Differences exist between age groups regarding personal viewpoints about whistleblowing. It appears that older employees have different perceptions about whistle-blowing when compared to their younger counterparts. Management should thus ensure that policies and practices in the organisation encourage whistleblowing among all age groups. The new dispensation in the country which emphasises transparency, equal rights and ethical values could have contributed to the fact that "younger" employees have different perceptions about whistle-blowing compared to those of "older" employees who have grown up under the old dispensation.

- Personal viewpoints of respondents regarding whistleblowing also show significant relationships with their number of dependants $\left(\mathrm{HO}_{2}\right.$ rejected). Employees with no dependants have different perceptions about whistleblowing when compared to those who have dependants. This might relate to the fact that employees with no dependants feel that they have nothing to lose in reporting wrongdoing (if they lose their job they have no dependants to care for), while, those with dependants are more reluctant to report wrongdoing (fear they may lose their job and cannot support their dependants). Organisational policies regarding whistle-blowing should explicitly state that there are no harmful consequences if the whistle is blown (not even losing one's job). Job security should be ensured at all times.

- Highly significant relationships were found between ethnic groups and personal perceptions regarding whistle-blowing $\left(\mathrm{HO}_{3}\right.$ rejected). Ethnic groups differ regarding their personal viewpoints about reporting wrongdoing. Employers should be sensitive and open towards differences between ethnic groups regarding ethical issues. Contemporary organisations should, therefore, without becoming too ethnically or race-orientated, attempt to cater for and align ethnic differences with organisational and ethical values. Sensitivity towards ethnic differences could foster an environment in which whistle-blowing is encouraged and practised.

- The personal viewpoints of employees regarding whistleblowing in the workplace showed highly significant relationships with the position occupied in the organisation $\left(\mathrm{HO}_{4}\right.$ rejected). Differences exist between employees, managers and owners regarding their personal viewpoints about whistle-blowing. The practice of whistle-blowing should therefore be encouraged and promoted among all levels in the organisation. The perception might exist that employees are more likely to report wrongdoing than managers who often "hide" wrongdoings or perhaps are more likely to be involved in wrongdoing due to access to information based on their status. Employees at all levels should be encouraged to blow the whistle, even if exposing the wrongdoings of management.

- There appears to be a significant relationship between the personal viewpoints of employees regarding whistleblowing in the workplace and income level $\left(\mathrm{HO}_{5}\right.$ rejected). Employees with different income levels differ in their personal viewpoints about whistle-blowing. Employees with lower levels of income might feel that they have nothing to lose when blowing the whistle, while employees with higher levels of income might be more reluctant to report wrongdoing, as they have a lot at stake. Employees should be assured and encouraged that regardless of income level,

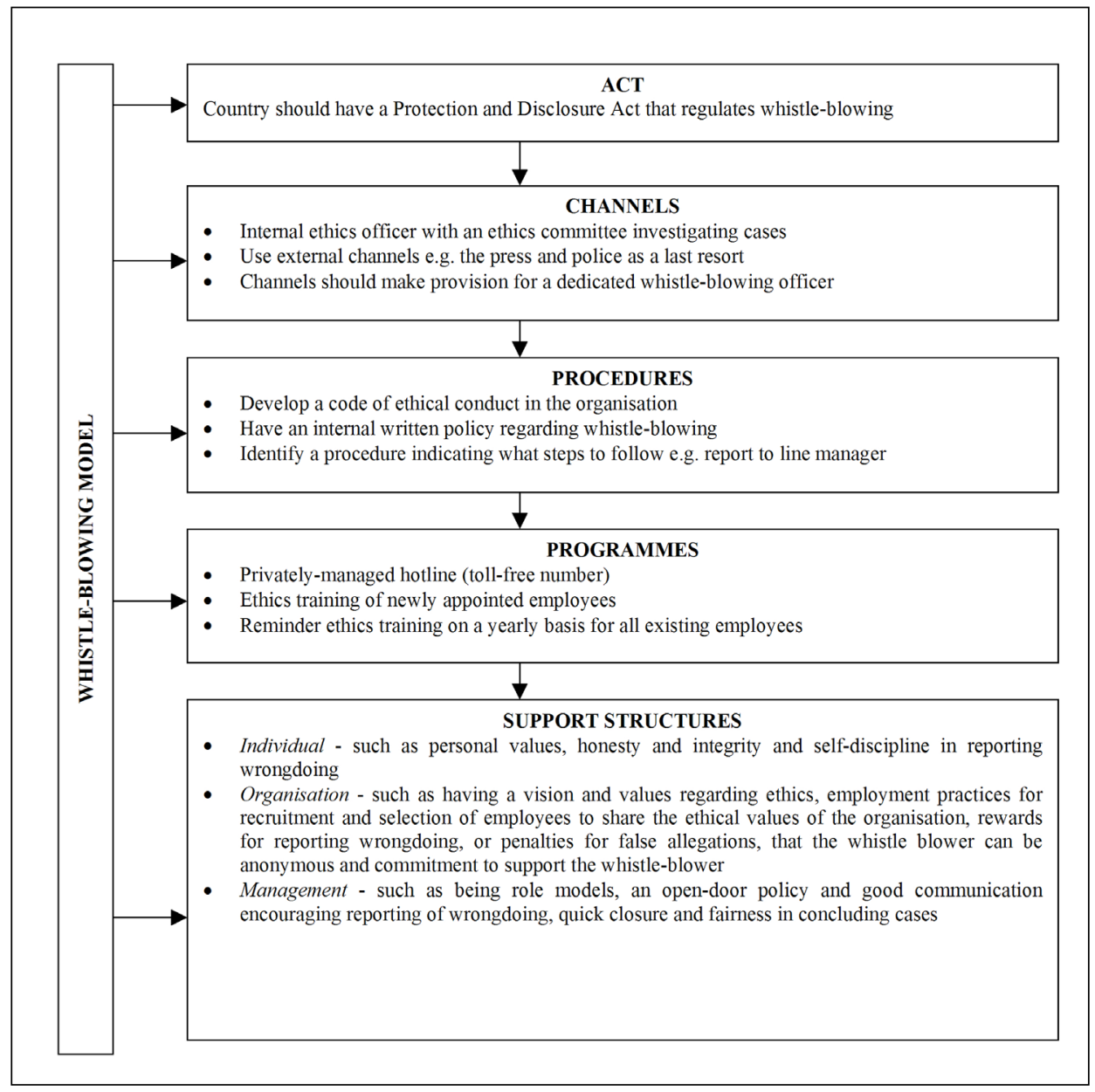

FIGURE 3

Model for practising whistle-blowing in the workplace 
everyone in the organisation has a right and obligation to report wrongdoing.

- A supportive environment for whistle-blowing showed a significant relationship with the ethnic group of respondents $\left(\mathrm{H} 0_{6}\right.$ rejected). It appears that employees from different ethnic groups value different aspects of a supportive environment regarding whistle-blowing as being important. Organisations should therefore be ethnically sensitive when creating and providing a supportive environment for whistle-blowing.

- It was found that there is a highly significant relationship between a supportive environment for whistle-blowing and the position of respondents in the organisation $\left(\mathrm{HO}_{7}\right.$ rejected). Owners, managers and employees differ in their perceptions regarding a supportive environment for whistle-blowing. Lower-level employees might feel more vulnerable when reporting wrongdoing and therefore require more support when compared to managers and owners. Lower-level employees should be ensured that they can rely on the support of the organisation and other role players when blowing the whistle.

- There appears to be a significant relationship between a supportive environment for whistle-blowing and the length of employment of respondents $\left(\mathrm{HO}_{8}\right.$ rejected). Employees with different lengths of employment differ in their perceptions regarding a supportive environment for whistle-blowing. Employees with a shorter tenure might be more dependent on a supportive environment for whistle-blowing as they feel more exposed and stand a chance of more easily being fired for reporting wrongdoing. Employees with longer tenures know the ropes and are therefore less dependent on a supportive environment.

- There is a highly significant relationship between a supportive environment for whistle-blowing and the income level of respondents $\left(\mathrm{HO}_{\mathrm{g}}\right)$. Employees with lower income levels are likely to be more dependent on a supportive environment when reporting wrongdoing, as they fear that they might lose their job. Employees at all income levels should be given the assurance that they can rely on the support of the organisation and various role players when blowing the whistle.

There has been an increase in whistle-blowing in South Africa in the workplace as the majority of respondents have blown the whistle internally in the last 10 years. This was brought about by countries promulgating Acts to this effect. Many reasons were given as to why employees have blown the whistle, but it is clear that employees should value ethics and honesty in the workplace from a personal viewpoint and also think in terms of the long-term reputation, goals and best interest of the organisation. It is acknowledged that both the organisation and the individual could benefit in the long run. The majority of respondents of this study are still employed by the organisation and were treated fairly. Respondents that have not yet blown the whistle, are not fully aware of the consequences thereof. Those respondents who blew the whistle are aware of the negative consequences of whistle-blowing: getting into trouble, dismissal, lack of union protection, lots of pressure, fear, being the outcast and being victimised by a supervisor. Unions in South Africa do not totally support whistle-blowers as only about half of respondents who blew the whistle indicated that they had union protection. This indicated that unions are not yet very familiar with whistle-blowing procedures and cases. Respondents also acknowledged the positive consequences of whistle-blowing such as bringing about change in the work place, making people alert and benefiting the organisation in the long run. In spite of the negative consequences, the vast majority would blow the whistle again as it appears that most organisational cultures support whistle-blowing. The organisational culture of the organisation will determine if those who have blown the whistle will do so again. Few respondents indicated that they would not blow the whistle again because they had a bad experience, cannot afford to lose their job, or as their innocence was turned into suspicion.

The results of the study revealed that whistle-blowing can be improved in the following ways:

- The workplace must have a personal code of ethics, based on guidelines from the Act;

- The internal policy must include a clear statement that malpractices are taken seriously and confidentiality is respected so as to prevent whistle-blowing externally;

- The internal system should have proper communication channels and the organisation should have a supportive environment starting with the incorporation of ethical conduct in their vision and value statements;

- An ethical committee should be established and be responsible for ensuring that systems are in place. This committee should choose a dedicated ethics officer to whom wrongdoings in the organisation can be reported;

- The process to resolve wrongdoings has to be dealt with professionally, with commitment from top management;

- At all times, management should have an open-door policy regarding employee complaints;

- Allegations must be investigated promptly and thoroughly;

- The individual blowing the whistle must act with honesty and integrity and there should be penalties for false allegations and rewards for bringing justice;

- Ethics training, in particular on whistle-blowing, should be given to new and existing employees on a periodic basis to raise awareness and as reinforcement of ethical principles;

- Mechanisms such as a toll-free number (hotline) managed by a private company, access to independent advice, guidelines on how to raise concerns outside the organisation if necessary, should be indicated;

- An ethical audit should be conducted annually and visible steps be taken to address concerns raised.

Figure 3 provides a model to minimise wrongdoing in the workplace and encourage whistle blowing.

The following quote is appropriate to conclude this article: "It is believed that whistle-blowers are not any different from other employees. They do not seem to be at a higher stage of moral development, nor are they either more or less loyal to the company than their peers. Instead they tend to be people who happen to know about the wrongdoing and believe that by acting they can do something to stop it."

(Hellriegel, et al.,2004, p. 138).

\section{REFERENCES}

About De Beers. (2005). Retrieved September 17, 2007, from the World Wide Web: http://www.debeersgroup. $\mathrm{com} /$ debeersweb/about+De+Beer+Value+and+Culture / The+Assurance+Programme.htm

Auriacombe, C.J. (2005). What happens when one blows the whistle? Recent South African cases. Sabinet online, 24(1), 85-100. Retrieved September 5, 2007, from the World Wide We b: http://www.subinet.co.za/abstracts/polit/polit_v24_ n1_95_htm.

Bakman, F. (2003). The impact of whistle-blowing on organisations. Unpublished masters research proposal papers. Johannesburg: Rand Afrikaans University.

Barker, R., \& Dawood, R. (2004). Whistle blowing in the organisation: wrongdoer or do-gooder? Communicare, 23(2), 119-138.

Borrie, G. \& Dehn, G. (2003). Whistle-blowing: the new perspective. Retrieved September 16, 2007, from the World Wide Web: http://www.pcaw.co.uk/policy-pub/ niewperspective.html.

Brian, D. (2001). The future of organisation ethics in Africa. IBER, 4(1). Retrieved September 5, 2007, from the World Wide Web: http://www. Organization-ethics.org/newdetail. asp?newsld $=20-27 \mathrm{k}$. 
Camerer, L. (1996). Ethics and the professions: blowing the whistle on crime. African security review, 5(6). Retrieved September 10, 2007, from the World Wide Web: http://www. iss.co.za/pubs/ASR/5/No6/Camerer.html.

Camerer, C. (2001). Protecting whistle blowers: the protected disclosures Act. Organization day, 7 Feburary, p. 21.

Carroll, A.B., \& Buchholtz, A.K. (2000). Organization and society. (4th Ed.). Mason: South Western College.

Caslon Analytics guide secrecy and accountability. (2000) Retrieved April 30, 2008, from the World Wide Web: http:// www.cslon.com.am/secresyguide1-.htm.

Classified and related information disclosure Act. (1998) Retrieved April 30, 2008, from the World Wide Web: http:// www.fas.org/sgp/congress/s1668.htm.

Daft, R.L. (2006). The new era of management. International edition. Australia: South Western Thompson.

Dellaportas, S., Gibson, K., Alagiah, R., Hutchinson, M., Leung, P., \& Van Homrigh, D. (2005). Ethics, governance and accountability: A professional perspective. Australia: John Wiley \& Sons, Ltd.

Dom, E. (2007). AIU Africa Compliance Flash. Retrieved September 18, 2007 from the World Wide Web: http:// www. aigcompliancehelpline.com

Eaton, T., \& Akers, M.D.( 2007). Whistleblowing and good governance, CPA Journal, 77(6), 66-71.

Hair, J.F., Anderson, R.E., Tatham, R.L., \& Black, W.C. (1998) Multivariate data analysis. New Jersey: Prentice Hall, Inc.

Hellriegel, D., Jackson, S.E., Slocum, J., Staude, G. \& Associates (2001). Management. Cape Town: Oxford University Press.

Hellriegel, D., Jackson, S.E., Slocum, J., Staude, G. \& Associates (2004). Management. Cape Town: Oxford University Press.

Hills Covernance Centre (2004). Whistleblowing in the Philippines Awareness, Attitudes and Structures. Retrieved April 1, 2008, from the World Wide Web: http://www.Aimshills.ph/proejectpage/prs/research3_6htm..

Investing in the future. (2005). Retrieved September 17, 2007, from the World Wide Web: http://Debeersgroup.com/ debeersweb/Investing+in+the+future/Ethics?Whistle_ blowing.htm.

Kaplan, B., \& Kleiner, B.H. (2000). New developments concerning discrimination for whistle blowing, Insight, 19(6-7), 75-77. Retrieved September, 10, 2007 from the World Wide Web: http://www.emraldinsight.com/ uinsight/viewPDF.jsp?filename=html/output/published/ EmraldAbstractOnlyArticle/pdf/0300190616.pdf.

Martens, L.T., \& Crowell, A. (2002). Whistle blowing: A global perspective. Retrieved July 23, 2007, from the World Wide Web: http://www.info.ethicspoint.com/pyw9d...

Megone, C. \& Robinson, S.J. (2002). Case histories in organization ethics. (1st Ed.). Oxon: Routledge.

Moon, C., \& Bonny,C. (2001). Organization ethics. London: Profile Books.

Nadler, J., \& Schulman, M. (2006). Whistle blowing in the public sector. Markkula Centre for Applied ethics. Retrieved September 17, 2007 from the World Wide Web: http://www. scu.edu/ethics/practicing/focusareas/government.
Naude, P.J. (2005). Organisation ethics: an orientation Unpublished organisation ethics study guide. Port Elizabeth: Nelson Mandela Metropolitan University.

Nelson, K., \& Trevino, L. (2007). Managing organization ethics: straight talk about how to do it right. (4th Ed.). Sydney: John Wiley and Sons.

Organization Ethics policy. (2005). Retrieved September 12, 2007, from the World Wide Web: http://www.g4s.com/home/crs/ cer-organizationethics-policy.htm\#csr-organizationethicspolicy-policies.

Organizations learn ethics make good organization sense (2003). Retrieved September 7, 2007, from the World Wide Web: http://www.gsb.uct.ac.za/gsbwebb/suerfiles/ organizationslearnethicsmakegoodorganizationsense_ 1.pdf.

Policy and procedures on whistle-blowing: Definition. (1999). Retrieved July, 23, 2007 from the World Wide Web: http:// www.bhasvic.ac.uk/govenors/Policy\%20File\%20Januar y\%202008/HUMAN\%20RESOURCES/Whistleblowing Policy_and_Procedures.pdf

Ravishankar, L. (2002). Encouraging internal whistle-blowing in organsations. Retrieved September 16, 2007, from the World Wide Web: http://www.scu.edu/ethics/p;ublications/ submitted/whistleblowing.html.

Robbins, S.P., \& Judge, T.A. (2006). Organizational behaviour. (12Ed.). New Jersey: Pearson Education.

Royal Kingston. (2007). What takes place in an investigation. Retrieved May, 5, 2008 from the World Wide Web: http://www.kingston.gov.uk/.../key_documents_for_ procurement/whistleblowing/the_whistleblowing process.htm.

Rossouw, D. (2002). Organization ethics in Africa. (2nd Ed.). Cape Town: Oxford University Press.

Rossouw, D. \& Van Vuuren, L. (2004). Organization ethics. (3rd Ed.). Cape Town: Oxford University press Southern Africa.

Sangweni, S. (2005). Parliamentary briefing on the 2005 Annual state of the Public service Report. Retrieved September 17, 2007, from the World Wide Web: http://www..pmg.org.za/ briefings/briefings.php?id=185.

Stewart, D. (1996). Organization ethics. United states of America: McGraw-Hill Companies, Inc.

Ten things you can do to avoid being the next Enron. 2005. Retrieved September 17, 2007, from the World Wide Web: http://www.Ethics.org/resources/avoid-being-enron.asp.

Weiss, J.W. (2006). Organization ethics. (4th Ed.). Ontario: Thompson/South West.

Whistleblowers. (2007). Retrieved September 12, 2007, from the World Wide Web: http://www.whistleblowing.co.za/site/ awdep.asp?dealer $=6565 \&$ depnum $=20401$ whistleblowers.

Whistleblowing Act No. 26. (2000). Retrieved October 2, 2007, from the World Wide Web: http://www. Nacf.org.za/guide_ to_the_whistle_blowing_act/section_two.html.

Wood, M.B. ( 2004). Organization ethics in uncertain times. New Jersey: Pearson Education. 